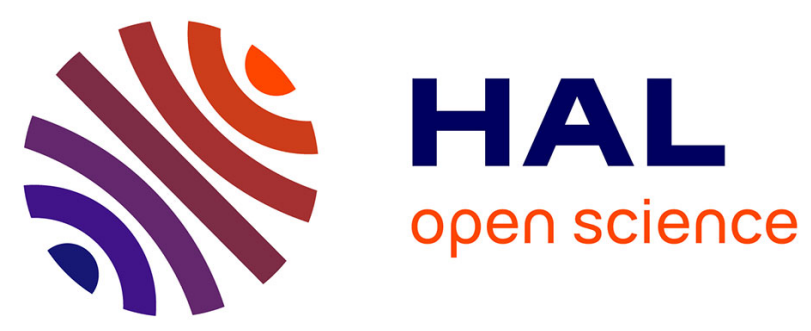

\title{
Superparamagnetic nanohybrids with cross-linked polymers providing higher in vitro stability
}

Weerakanya Maneeprakorn, Lionel Maurizi, Hathainan Siriket, Tuksadon

Wutikhun, Tararaj Dharakul, Heinrich Hofmann

\section{To cite this version:}

Weerakanya Maneeprakorn, Lionel Maurizi, Hathainan Siriket, Tuksadon Wutikhun, Tararaj Dharakul, et al.. Superparamagnetic nanohybrids with cross-linked polymers providing higher in vitro stability. Journal of Materials Science, 2017, 52 (16), pp.9249-9261. 10.1007/s10853-017-10982. hal-02163533

\section{HAL Id: hal-02163533 \\ https://hal.science/hal-02163533}

Submitted on 11 Mar 2021

HAL is a multi-disciplinary open access archive for the deposit and dissemination of scientific research documents, whether they are published or not. The documents may come from teaching and research institutions in France or abroad, or from public or private research centers.
L'archive ouverte pluridisciplinaire HAL, est destinée au dépôt et à la diffusion de documents scientifiques de niveau recherche, publiés ou non, émanant des établissements d'enseignement et de recherche français ou étrangers, des laboratoires publics ou privés. 


\title{
Superparamagnetic nanohybrids with cross-linked polymers providing higher in vitro stability
}

W. Maneeprakorn, ${ }^{a}$ L. Maurizi, ${ }^{\mathrm{b}}$ H. Siriket, ${ }^{a}$ T. Wutikhun, ${ }^{a}$ T. Dharakul, ${ }^{\mathrm{a}, \mathrm{c}}$ and H. Hofmann ${ }^{\mathrm{b}}$

\begin{abstract}
A method for facile synthesis of high stable cross-linked superparamagnetic nanohybrids using pre-coating of biocompatible polymer, hydroxyl polyvinyl alcohol (PVA-OH) was demonstrated as a simple, controllable, fast, reproducible, and upscalable method. To improve stability, morphology and functionalization of the particles, the PVA-OH was first coated onto superparamagnetic iron oxide nanoparticle (SPION) surfaces before a cross-linking condensation with silica precursor. The obtained magnetic nanohybrid with compact silica layer was monodispersed with uniform morphology with the size of 50.0 $\pm 3.7 \mathrm{~nm}$. The particles showed colloidal stability region at $\mathrm{pH} 7.35-7.45$ which is applicable in biomedical applications and long shelf life upon storage of over 9 months. In vitro study in aspect of cytotoxicity and stability of the particle reveled that these original nanohybrids are non-toxic and highly robust in endosomal/lysosomal condition for up to 42 days without dissolution of the particles. In order to demonstrate the efficient targeting of the magnetic nanohybrid for their further use as targeting detection for example in MRI, we prepared folate reactive cross-linked magnetic nanohybrid which showed an interesting affinity to folate receptor (FR)-positive cervix (HeLa) cells. Our work to develop the characteristics of non-toxic and stable cross-linked magnetic nanohybrids would be beneficial for the further development of safer and more efficient targeting MRI contrast agent for diagnosis of various cancers.
\end{abstract}

\section{Introduction}

Superparamagnetic iron oxide nanoparticles (SPIONs) have received a growing interest for various biomedical applications such as magnetic resonance imaging (MRI), ${ }^{1,2}$ cell sorting, ${ }^{3}$ magnetic separation, ${ }^{4}$ biosensing, and therapy. ${ }^{5,6}$ Among those applications, SPIONs are particularly useful as MRI contrast agents because of their strong magnetic properties, desirable biocompatibility and biodegradability properties. ${ }^{7,8}$ However, the naked SPIONs are not stable and generally form sediment under physiological conditions that can impede blood vessels especially for clinical applications. ${ }^{9}$ Thus, the surfaces of SPIONs are essential to tailor to improve the stability, biocompatibility, biodegradability, and biodistribution of the particle in vivo. Commercially available SPION-based MRI contrast agents in target organ are surface coated with biocompatible materials such as dextran, carboxy dextran and carbohydrate polyethylene glycol (PEG). ${ }^{10}$ Dextran can improve the blood circulation time, stability, and biocompatibility of SPIONs. ${ }^{11}$ However, they are not stable and can leach from coating matrix. There are evidences that coating material such as dextran and carboxy dextran are not strongly bound on iron oxide nanoparticles and tends to detach. ${ }^{12-14}$ Hydrophilic polymer coating, such as polyethylene glycol (PEG) and poly(vinyl alcohol) (PVA) have been widely used to cover SPION surfaces. Although, PEG coating can enhance the hydrophilicity and water-solublility, improve the biocompatibility, and blood circulation times, ${ }^{15,16}$ it can induce anti-PEG antibodies that accelerate the clearance and reduce the efficacy of the nanoparticle conjugates. ${ }^{17}$ Recently, PVA, a biodegradable, biocompatible, water-soluble, and inexpensive polymer, has been increased in attention due to a good interaction with metal oxide nanoparticles. ${ }^{18,19}$ Colloidal stability, monodispersibility, and biocompatibility of iron oxide nanoparticles were improved after PVA coating. ${ }^{20,21} \mathrm{~A}$ previous study reported the advantages of using PVA as a coating material of SPIONs for preparation of robust magnetic iron oxide-PVA gel beads for drug delivery application with tunable drug release rate. Also, SPIONs coated with amino-polyvinyl alcohol (A-PVA) was found to be non-toxic to cells allowing usability of SPIONs in vivo. For example, A-PVA-SPIONs showed efficient internalization by mesenchymal stromal cells (MSCs) without cell toxicity and the need to use transfection agents. In addition, ${ }^{23}$ A-PVA-SPIONs were found to accumulate in bone marrow and increase the bone marrow stromal cells (BMSCs) metabolic activity and migration rate enabled the suitability of A-PVA-SPIONs for MRI contrast enhancement in bone marrow. ${ }^{24}$

Apart from hydrophilic polymers, an inorganic layer such as silica metal is considered to be an alternative candidate for surface coating of SPIONs. Practically, this coating not only provides the stability and biocompatibility to the SPIONs, but also helps in covalent binding the various biological or the other ligands at the SPION surface allowing different kinds of bioapplications. ${ }^{25}$ There are many approaches to generate silica nanoshell including, sol-gel method, ${ }^{26-27}$ emulsion method, ${ }^{28-29}$ and pyrolysis method. ${ }^{30}$ However, these methods are complicated and require long reaction time for coating of silica. Moreover, they are difficult to scale-up and reproduce. Generally, classical sol-gel method requires several steps and long synthesis time of $6-48$ h. ${ }^{27}$ Other methods such as an emulsion method and aerosol pyrolysis also requires long reaction times (16-48 h), ${ }^{29}$ and provide a low amount of the particle products. At present, sol-gel method has been used extensively for silica coating because of mild reaction condition, low cost, and surfactant-free media. For this method, silica layer was formed through the hydrolysis and condensation of a solgel precursor, in alcoholic basic condition. ${ }^{31}$ However, noble metal nanoparticles are not stable in alcoholic solution and have low chemical affinity for silica. This could result in low production yield and unpacked silica layer which effect the stability of the particles regarding to their shelf-life and their breakdown in vitro or in vivo. ${ }^{32}$ Recently, we reported the silica coating method with improved production yield and reproducibility by using pre-functionalizing mixed-PVA (hydroxyl polyvinyl alcohol (OH-PVA) and amino PVA (A-PVA)) on SPION surfaces as the iron core followed by the hydrolysis condensation reaction using tetraethyl orthosilicate (TEOS) as 
the silica precursor in ethanoic solution. The method provided a non-cytotoxic raspberry-like shape silica coated PVA-SPIONs with the high rate of internalization of the particles into various cell types. ${ }^{33}$ In addition, the method was improved to one-step reaction for preparation of silane-coated silica encapsulated PVA-SPIONs by using silica (TEOS) and amino-silica ((3aminopropyl)triethoxysilane, APTES) precursor together instead of silica precursor solely. ${ }^{34}$ Also, this method allowed reproducibility and easy scale-up for preparation of the biocompatible silica coated SPIONS.

In this work, we improved our previous silica coating to be an easier, gram-scaled, and reproducible method for a welldefined core shell structure of silica coated PVA-SPION synthesis by using pre-coating hydroxyl-PVA-SPIONs (OH-PVASPIONs) as the core particle. Some aspects associated with the cytotoxicity and colloidal stability of the particles in physiological conditions and endosomal/lysosomal environment were elucidated. The potential of the particles for biomedical application such as targeted MRI contrast agent was also demonstrated by functionalizing the particles with folic acid to become folate-reactive particles. The affinity of the folate-reactive nanohybrid particles to folate receptor (FR)positive cervix (HeLa) cells was investigated in vitro. By taking the advantages of OH-PVA stabilization together with silica coating, high stable cross-linked magnetic nanohybrids with no cytotoxicity and long shelf life were obtained.

\section{Experimental}

\section{Materials and characterizations}

Iron (III) chloride hexahydrate $\left(\mathrm{FeCl}_{3} \cdot 6 \mathrm{H}_{2} \mathrm{O}\right)$, iron (II) chloride tetrahydrate $\left(\mathrm{FeCl}_{2} .4 \mathrm{H}_{2} \mathrm{O}\right)$, iron (III) nitrate nonahydrate $\left(\mathrm{Fe}\left(\mathrm{NO}_{3}\right)_{3} .9 \mathrm{H}_{2} \mathrm{O}\right)$, tetraethyl orthosilicate (TEOS), (3aminopropyl)triethoxysilane (APTES), sodium chloride $(\mathrm{NaCl})$, and folic acid (FA) were purchased from Sigma-Aldrich. Ammonium hydroxide $\left(\mathrm{NH}_{4} \mathrm{OH}\right)$, trimethylamine $\left(\mathrm{N}\left(\mathrm{CH}_{3}\right)_{3}\right)$, and potassium ferrocyanide $\left(\mathrm{K}_{4}\left[\mathrm{Fe}(\mathrm{CN})_{6}\right]\right)$ were purchased from Merck, while hydrochloric acid and ethanol were purchased from Carlo Erba. Nitric acid $\left(\mathrm{HNO}_{3}\right)$ was purchased from J.T. Baker. Hydroxyl polyvinyl alcohol (OH-PVA), Mowiol 3-85 was supplied by Kuraray Europe $\mathrm{GmbH}$. All reagents were used as received without further purification. All aqueous solutions were prepared with ultrapure water from a Milli-Q system (Millipore). All media and cell culture components (RPMI-1640, Fetal bovine serum (FBS), penicillin G, and streptomycin) and PrestoBlue cell viability reagent were obtained from Life Technologies. The morphology and structure the particles were characterized with transmission electron microscope operated at 200kV (TEM, JEM 2100, JEOL Ltd., Japan). Hydrodynamic diameter (number weighted) and Zeta potential were investigated by dynamic light scattering using a Zeta Nanosizer (Malvern Instruments, UK). The iron concentration ([Fe] in $\mathrm{mgFe} / \mathrm{mL}$ ) was measured by Prussian blue colorimetric assay using the reaction between $\mathrm{K}_{4}\left[\mathrm{Fe}(\mathrm{CN})_{6}\right]$ and $\mathrm{Fe}^{3+}$ to give a blue product called Prussian blue $\left(\mathrm{Fe}_{4}\left[\mathrm{Fe}(\mathrm{CN})_{6}\right]_{3}\right)$ and the optical density of the blue product was measured at $690 \mathrm{~nm}$ using microplate spectrophotometer (BioTek Instrument, USA). For cytotoxicity experiments, fluorescence measurements was performed using a microplate reader (SpectraMax M2, Molecular Devices LLC, Sunnyvale, CA) and real time cell monitoring was recorded using real time cell analyzer (RTCA) (xCELLigence, ACEA Biosciences, San Diego, CA).

\section{Starting material preparation}

PVA coated SPIONs (PVA-SPIONs). SPIONs were obtained from a known classical co-precipitation method described elsewhere. ${ }^{23,34}$ PVA-SPION suspension was prepared by mixing OH-PVA and SPIONs at a mass ratio PVA/Fe of 9. Briefly, equivolumes of SPIONs (at $10 \mathrm{mgFe} \mathrm{mL}^{-1}$ ) and OH-PVA (at $90 \mathrm{mgPVA}$ $\mathrm{mL}^{-1}$ ) were mixed and stored at $4^{\circ} \mathrm{C}$ for at least one week before further use to let the equilibration of the PVA adsorption onto SPIONs. ${ }^{35}$

\section{Synthesis of silica cross-linked PVA-iron oxide nanohybrids (Silica- CL-PVA-SPIONS)}

Silica-CL-PVA-SPIONs were synthesized from a cross-linking condensation of silica precursor onto PVA-SPIONs (Scheme 1). In a typical experiment, $10 \mathrm{~mL}$ of PVA-SPIONs $\left(4.5 \mathrm{mgFe} \mathrm{mL}^{-1}\right.$ PVA-SPIONs) were suspended in $3600 \mathrm{~mL}$ of water and ethanol ( $\mathrm{v} / \mathrm{v} ; 1: 3)$ and mixed by sonication. Next, $3.75 \mathrm{~mL}$ of TEOS and $40 \mathrm{~mL}$ of $\mathrm{NH}_{4} \mathrm{OH}$ were added to the suspension, respectively, and mixed at room temperature under sonication for $1 \mathrm{~h}$. The suspensions were washed 3 times using water with $30 \mathrm{~min}$ of centrifugation at $15,000 \mathrm{~g}$. The Silica-CL-PVA-SPION suspension was redispersed in $10 \mathrm{~mL}$ of water to give the final concentration of $3.4 \mathrm{mgFe} \mathrm{mL}^{-1}$ at $\mathrm{pH} 8$.

Scheme 1 Schematic diagram of silica cross-linked PVA-iron oxide nanohybrids (Silica-CLPVA-SPIONS).

\section{Cytotoxicity study}

Cytotoxicity study was conducted in human cervical cancer cell (HeLa cells). The cultured cells were kept at $37^{\circ} \mathrm{C}$ in a humidified $\mathrm{CO}_{2}$ incubator during the culture and the experiments. For cell viability study, PrestoBlue assay was performed. Cells were seeded at a density of $4.0 \times 10^{4}$ cells per well in flat-bottomed 96-well plates and treated with the nanoparticles at a range of concentrations (0-125 $\mu \mathrm{gFe} \mathrm{mL} \mathrm{m}^{-1}$ ), allowed to grow for a further 24 h., washed once with phosphate buffered saline (PBS) to remove excess nanoparticles and replaced with fresh medium containing the PrestoBlue cell viability reagent according the manufacturer's specifications. The fluorescence of each well was measured in a microplate reader at excitation and emission wavelength of 560 and 590 $\mathrm{nm}$, respectively. For monitoring toxicity of cells during cultures, real time cell analyzer (RTCA) was used. The detailed experiments on cytotoxicity were shown in electronic supplementary information (ESI)

\section{Stability and degradation of the particles}

The colloidal stability of the particles was investigated by studying the effects of $\mathrm{pH}$ and ionic strength on stability of the dispersion. The Zeta potential and the size distribution of nanoparticles exposed to a range of pHs from 2 to 12 and to different $\mathrm{NaCl}$ concentrations (from 0 to $1 \mathrm{M}$ ) were measured using a Zeta Nanosizer. 


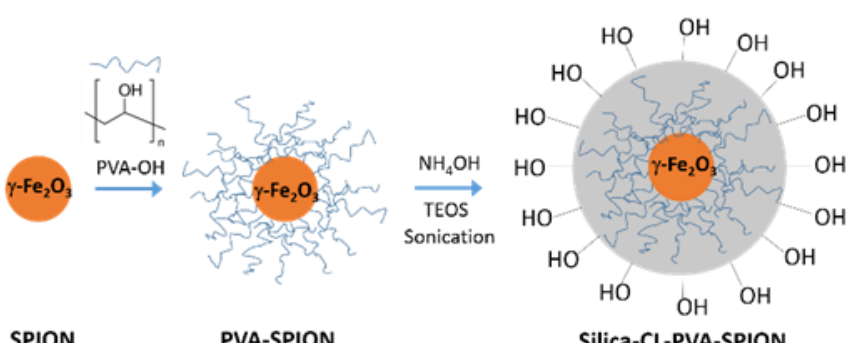

For stability of the particles in the acidic lysosomal microenvironment, a degradation of the nanoparticles in a model of lysosomal environment was performed based on previously described procedures. ${ }^{12,3}$ Seven reagents were prepared: (a) RPMI-1640 at pH 7.4; (b) RPMI-1640 at pH 5.5; (c) RPMI-1640 at pH 4.5; (d) 20 mM sodium citrate in RPMI-1640 $\mathrm{pH}$ 5.5; (e) $20 \mathrm{mM}$ sodium citrate in RPMI-1640 pH 4.5; (f) 20 $\mathrm{mM}$ sodium acetate in RPMI-1640 pH 5.5; and (g) $20 \mathrm{mM}$ sodium acetate in RPMI-1640 pH 4.5. Concentrated $\mathrm{HCl}$ was added to adjust the $\mathrm{pH}$ of solutions (a)-(c), citric acid was added to adjust the $\mathrm{pH}$ of solutions (d) and (e), and glacial acetic acid was used to adjust the $\mathrm{pH}$ of solutions ( $\mathrm{f}$ ) and (g). Nanoparticles (50 $\mu \mathrm{g}$, Fe basis) were added to test tubes containing $1 \mathrm{~mL}$ buffers and incubated at $37^{\circ} \mathrm{C}$ for up to 56 days. At several time points, samples were taken for measurement of free iron ions in solution by Prussian blue colorimetric assay and observed for particle aggregation.

\section{Silica-CL-PVA-SPIONs as the targeting molecule}

Folic acid grafting on Silica-CL-PVA-SPIONs. Silica-CL-PVASPIONs were first functionalized with amine for further chemical linking. Briefly, $2 \mathrm{~mL}$ of Silica-CL-PVA-SPIONs were diluted in $60 \mathrm{~mL}$ ethanol and $10.5 \mathrm{~mL}$ of APTES and the reaction was stirred for $3 \mathrm{~h}$ at $37^{\circ} \mathrm{C}$. Then the suspension was centrifuge at $10,000 \mathrm{~g}$ for $15 \mathrm{~min}$, redispersed in water and magnetically washed three times and redispered in $2 \mathrm{~mL}$ DI water. The $\mathrm{pH}$ of the suspension was adjusted to 5 by adding $6 \mathrm{~N} \mathrm{HCl}$ and kept at $4^{\circ} \mathrm{C}$ overnight. The obtained particle was called $\mathrm{NH}_{2}$-Silica- $\mathrm{CL}-$ PVA-SPIONs at the concentration of $1.21 \mathrm{mgFe} \mathrm{mL}^{-1}$. Then, an activated folic acid (FA-NHS) was prepared according to Sonvico et al. ${ }^{36}$ and Yang et al. ${ }^{37}$ Then, $\mathrm{NH}_{2}$-Silica-CL-PVA-SPIONs was mixed with FA-NHS to get the Silica-CL-PVA-SPIONs-FA. The final concentration of the Silica-CL-PVA-SPIONs-FA is $0.89 \mathrm{mgFe} \mathrm{mL}^{-1}$ based on Prussian blue assay. The detailed experiments were shown in electronic supplementary information (ESI).

\section{Cellular internalization of the particles.}

To determine the iron uptake by cells, HeLa and A549 cell lines were used as FR-positive control and FR-negative control, respectively. Cells were seeded at a density of $1.0 \times 10^{5}$ cells per well in 12-well plates in folate-free culture medium and treated with nanoparticles at a range of concentrations $(0-125 \mu \mathrm{gFe} \mathrm{mL}$ 1). The cells were allowed to grow for a further $24 \mathrm{~h}$. and washed once with folate-free RPMI and then three times with PBS. The cultured cells were collected by trypsinization and digested. The solubilized iron ions were determined by Prussian blue colorimetric assay. Similarly, for the specific binding to folate receptor of the particles, cells were incubated with Silica-CL-
PVA-SPIONs-FA, Silica-CL-PVA-SPIONs or the mixture of SilicaCL-PVA-SPIONs-FA and folic acid (FA + Silica-CL-PVA-SPIONs-FA) for $4 \mathrm{~h}$. All cells were exposed to $15.6 \mu \mathrm{gFe} \mathrm{mL} \mathrm{m}^{-1}$ of the particles unless the FA + Silica-CL-PVA-SPIONs-FA which the cells were first treated with $0.125 \mu \mathrm{g} \mathrm{mL} \mathrm{m}^{-1}$ folic acid for $30 \mathrm{~min}$. before addition of Silica-CL-PVA-SPIONs-FA. Then, the cells were washed, harvested by trypsinization and digested. The solubilized iron ions were determined by Prussian blue colorimetric assay. All experiments were performed in triplicate. Cells that were not exposed to nanoparticles were used as the control experiment. Intercellular uptake of Silica-CLPVA-SPIONs-FA was studied by using TEM. The detailed experiments were shown in electronic supplementary information (ESI).

\section{Results and discussion}

\section{Nanoparticle synthesis and characterization}

The well-defined core-shell structured silica-coated SPIONs (Silica-CL-PVA-SPIONs) were prepared successfully by a crosslinking condensation of silica precursor onto the pre-coating hydroxyl-PVA-SPIONs (OH-PVA-SPIONs). We reported the gramscale and short reaction time synthesis by improving the conventional sol-gel process. Generally, the conventional solgel protocols for silica coating methods for example Stöber method are performed in alcoholic solution, where metal or metal oxide nanoparticles are not stable. Besides, metal nanoparticles have low chemical affinity for silica, thus, the directly coating of silica on metal surfaces are not as effective as expected. In this work, SPION surfaces were pre-coated by PVA to provide the particles with good dispersibility in water and alcohol mixed solution as well as prevent the aggregation of SPION during sol-gel reaction. Thus, using this particle as the metal core can improve the effectiveness of conventional solgel method. Our method was one step reaction with a good reproducibility and easy scaled-up without changes in morphology and size of the nanoparticle products. One synthesis batch allowed for the production of $50 \mathrm{~mL}$ volume at concentration of $4 \mathrm{mg} / \mathrm{mL}$ iron basis. The transmission electron microscope (TEM) image of PVA-SPIONs and Silica-CL-PVASPIONs are shown in Fig. 1(a)-1(b). Monodispered magnetic nanohybrids with smooth surfaces of silica were obtained. The diameter of uncoated PVA-SPION core was $7.2 \pm 2.5 \mathrm{~nm}$ and after coating with silica the size was increased to $50.0 \pm 3.7 \mathrm{~nm}$ with the average silica layer thickness of $11.2 \mathrm{~nm}$. The hydrodynamic diameter and zeta potential of uncoated and coated particles are shown in Fig.1(c). SPION coated with PVA$\mathrm{OH}$ showed increase in hydrodynamic size from $17 \pm 2 \mathrm{~nm}$ to 31 $\pm 2 \mathrm{~nm}$, while the hydroxyl group of PVA resulting in decrease of surface charge from $+32 \pm 1 \mathrm{mV}$ to $+17 \pm 1 \mathrm{mV}$ as compared to naked SPION core. This suggested successful encapsulating of polymer onto a SPION surfaces. After silica coating, the SilicaCL-PVA-SPION hydrodynamic diameter increases to $71 \pm 3 \mathrm{~nm}$. Also, the zeta potential of particle shows negative shift from +17 $\pm 1 \mathrm{mV}$ to $-42 \pm 1 \mathrm{mV}$ which confirm that the particles were covered by silica layer. 
In order to obtain the highly stable cross-linked magnetic nanohybrid, all parameters including the SPION core, silica precursor, ethanol to water ratio, ammonium solution, reaction time, and mixing method (stirring or sonicating) were optimized to get a compact silica layer. It is important to stress that under the same condition, core-shell nanoparticle was unable to form by using naked SPION as the core particles, while core-shell particles were achieved when using pre-coating PVA-SPIONs. However, different functional groups of PVA can provide different morphologies of silica layer of the core-shell nanostructures (Figure S1). There was the report that the presence of PVA can affect the condensation of the silica onto the SPION surfaces. ${ }^{18}$
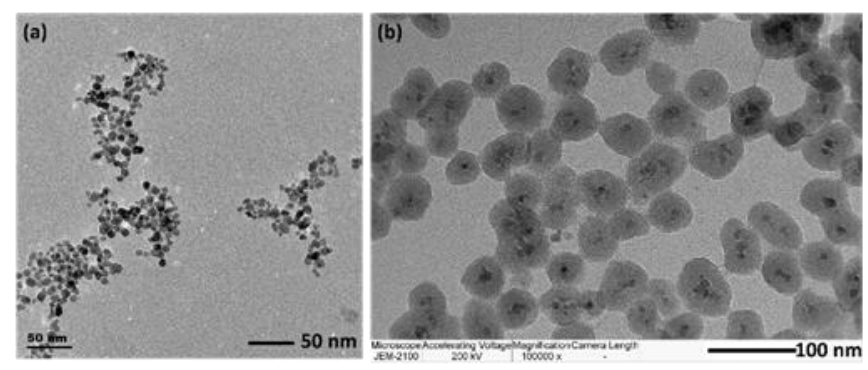

(c) \begin{tabular}{|c|c|c|c|}
\hline Particles & $\begin{array}{c}\text { Diameter by TEM } \\
{[\mathrm{nm}]}\end{array}$ & $\begin{array}{c}\text { Hydrodynamic diameter } \\
\text { (by number) [nm] }\end{array}$ & $\begin{array}{c}\text { Zeta potential } \\
{[\mathrm{mV}]}\end{array}$ \\
\hline SPIONs & $7.2 \pm 2.5$ & $17.39 \pm 2$ & $+32.47 \pm 0.7$ \\
\hline PVA-SPIONs & $7.2 \pm 2.5$ & $31.34 \pm 2$ & $+17.23 \pm 1.2$ \\
\hline Silica-CL-PVA-SPIONs & $50.0 \pm 3.7$ & $71.45 \pm 3$ & $-42.33 \pm 0.4$ \\
\hline
\end{tabular}

Fig. 1. TEM images of (a) PVA-SPIONs, (b) Silica-CL-PVA-SPIONs, and (c) summary of size and Zeta potential of particles measured in DI water.

In this work, we explored the effect of PVA functional group by using hydroxyl-PVA (OH-PVA) and mixture of carboxyl-PVA ( $\mathrm{COOH}-\mathrm{PVA})$ and hydroxyl-PVA (OH-PVA) called mixed-PVA coated SPIONs as the core particles. Our results revealed that an irregular porous silica layer was obtained by using mixedPVA-SPIONs instead of compact silica layer corresponding to our previous report using mixed-PVA coated SPIONs (the mixture of OH-PVA and A-PVA) on the preparation of the irregular raspberry-like porous silica coated-SPIONs. ${ }^{33}$ Meanwhile, the compact silica layer was obtained by using $\mathrm{OH}$ PVA-SPIONs solely. These results were attributed to the hydroxyl groups on both SPION and PVA which can facilitate the silica condensation. Another parameter that have the effect to the morphology of the particles is PVA to iron mass ratio (PVA/Fe) of PVA-SPIONs. Herein, the PVA/Fe ratio of 9 was selected as mentioned in our previous report that at this $\mathrm{PVA} / \mathrm{Fe}$ ratio, the core shell structure of silica coated SPION was achieved reproducibly.

\section{Cytotoxicity of the particles}

The cytotoxicity of the stabilized SPIONs (Silica-CL-PVASPIONs) was investigated. Real-time cell analyser (RTCA) was utilized to monitoring the dynamic response profile of living cells such as cell proliferation and death induced by toxicant. This system based on electrical impedance measurement on the bottom of cell culture plates. Impedance data created by attached cells are automatically converted to cell index value which is defined as relative change in electrical impedance created by cell. As cells detach and die, the cell-covered area reduces and cell index value decreases. 38,39
Fig. 2. (a) Dynamic monitoring of the cytotoxic response of HeLa cell exposed to different

(a)

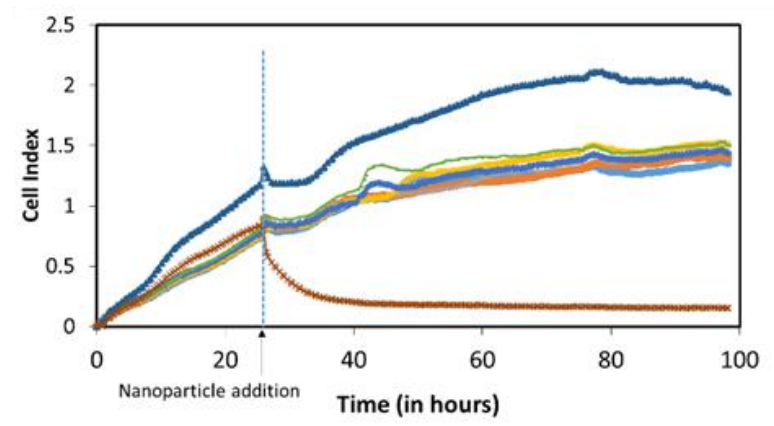

$\rightarrow 125 \mathrm{ugFe} / \mathrm{mL} \quad-62.5 \mathrm{ugFe} / \mathrm{mL} \quad-31.25 \mathrm{ugFe} / \mathrm{mL} \quad \rightarrow-15.625 \mathrm{ugFe} / \mathrm{mL}$

$\rightarrow 7.81$ ugFe $/ \mathrm{mL} \quad-3.8 \mathrm{ugFe} / \mathrm{mL} \quad \rightarrow 0 \mathrm{ugFe} / \mathrm{mL} \quad \rightarrow$ Triton X-100

(b)

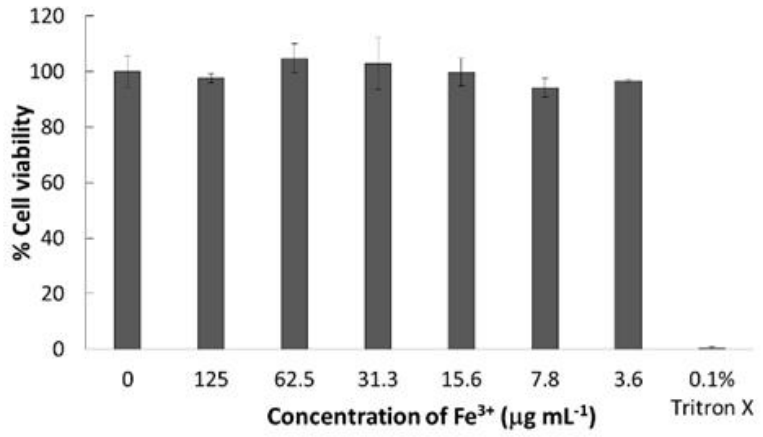

concentrations of Silica-CL-PVA-SPIONs. Cell index was monitored during $72 \mathrm{~h}$ after nanoparticle exposure. Reported data are the means of three replicates. (b) Cytotoxicity of Silica-CL-PVA-SPIONs using PrestoBlue assay.

Since the measurement is non-invasive and label free, the system can continuously monitor the cells from the time when they are seeded. ${ }^{40,41}$ The time-dependent concentration response of Silica-CL-PVA-SPIONs to HeLa cell using RTCA was shown in Fig. 2(a). The untreated control cells appeared healthy with good cell attachment at post growth time of $96 \mathrm{~h}$, while another control cell exposed to $0.1 \%$ Triton $\mathrm{X}-100$ instead of the nanoparticles showed dramatic decline in the cell index indicating cell death. The cells exposed to nanoparticles showed no decrease in cell index values for all concentrations revealed that Silica-CL-PVA-SPION was nontoxic. Cells continue to grow with no adverse effect until $72 \mathrm{~h}$ after nanoparticle addition. However, the cell index values are low as compared to an untreated control cells. A transient decrease of cell index value 
was observed after nanoparticle exposure, related to the interruption of impedance measurement during the nanoparticle addition. According to nanoparticles concentrations, kinetic profiles showed two transient decrease areas of cell index at 45-50 $\mathrm{h}$ and $77 \mathrm{~h}$, followed by an increase until the end of measurement. The transient decrease phase was observed obviously at $45 \mathrm{~h}$ for low concentrations (e.g. 3.8 and $7.81 \mu \mathrm{gFe} / \mathrm{mL}$ ).

In order to confirm the result from RTCA, an end-point PrestoBlue assay, a resazurin-based compound assay, which is converted to the reduced form by mitochondrial enzymes of viable cells was performed. Fig. 2(b) showed the data of cell viability of the HeLa cells after $24 \mathrm{~h}$ of incubation with the SilicaCL-PVA-SPIONs. HeLa cell with untreated particles was used as the control and the cell viability of which was set as $100 \%$. It was found that the Silica-CL-PVA-SPIONs had hardly any toxicity to the cells. In the presence of Silica-CL-PVA-SPIONs, the cell viabilities increased to be more than $90 \%$. The results from PrestoBlue assay showed a good consistency to RTCA indicated that Silica-CL-PVA-SPIONs exhibited no apparent cytotoxicity to HeLa cells and were favourably biocompatible.

\section{Colloidal stability of the particles}

Usually, SPION is sedimentary at physiological $\mathrm{pH}$ and reactive with chemical compounds of human organism and immune system. Our starting material, the PVA coating SPION was reported as the biocompatible coating materials. Also, silica is an inert and non-toxic material with high potential for functionalization with different ligands. The electrostatic repulsion mechanism at silica surface can prevent aggregation of particles at $\mathrm{pH}$ 7. Thus, by cross-linking silica to PVA-SPIONs, the biocompatibility and stability of the particles are expected to be improved. In order to demonstrate the colloidal stability of the particles, the effects of $\mathrm{pH}$ and ionic strength on colloidal stability of the particles were investigated. Silica-CL-PVA-SPIONs were exposed to a range of pHs from 2 to 12 and to different $\mathrm{NaCl}$ concentrations (from 0 to $1 \mathrm{M}$ ). Zeta-potential values and hydrodynamic size distributions of treated PVA-SPIONs and Silica-CL-PVA-SPIONs were represented on Fig. 3. The results in Fig. 3(a) revealed that PVA-SPION is stable at acidic $\mathrm{pHs}$ ranging from 2-6 and basic pHs ranging 9-12, whereas Silica-CL-PVASPIONs is stable at basic $\mathrm{pHs}(\mathrm{pH} 7-12)$. Comparing to uncoated Fig. 3 (a) The effects of pHs on colloidal stability of PVA-SPIONs and Silica-CL-PVA-SPIONs and (b) the hydrodynamic diameter size, polydispersity index (PDI), and Zeta potential of Silica-CL-PVA-SPIONs at different $\mathrm{NaCl}$ concentrations.

nanoparticles, Silica-CL-PVA-SPIONs show stability region at physiological $\mathrm{pH}$ of 7.35 to 7.45 with high negative zeta potential around $-37 \mathrm{mV}$ and point of zero charge $(\mathrm{PZC})$ at $\mathrm{pH} 3$, while PVA-SPIONs have zero potential point at $\mathrm{pH}$ around 7.5. This proves a necessity of silica coating and the efficiency of silica to stabilize the nanoparticles at physiological $\mathrm{pH}$. The hydrodynamic diameter size, polydispersity index (PDI), and Zeta potential of the Silica-CL-PVA-SPIONs at different $\mathrm{NaCl}$ concentrations were shown in Fig. 3 (b). Although, the Zeta potential of the particles decreased as the concentration of $\mathrm{NaCl}$ increased, the size of Silica-CL-PVA-SPIONs remains almost (a)

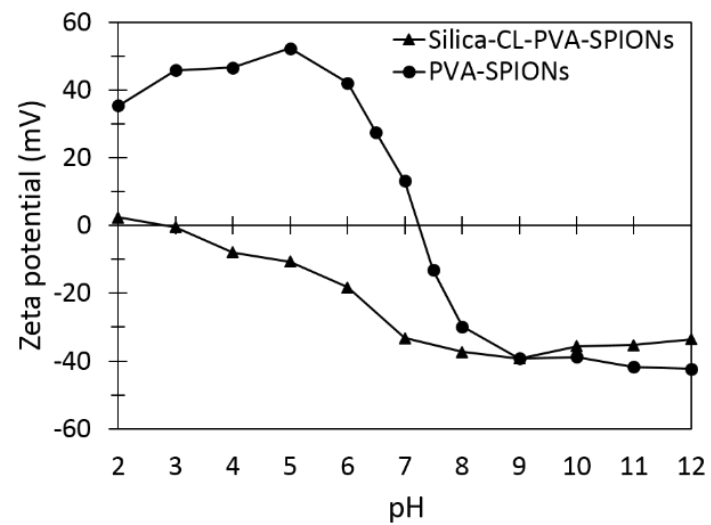

(b)

\begin{tabular}{|c|c|c|c|}
\hline $\begin{array}{c}\mathrm{NaCl} \\
\text { concentration } \\
{[\mathrm{M}]}\end{array}$ & $\begin{array}{c}\text { Hydrodynamic } \\
\text { diameter (by } \\
\text { number) [nm] }\end{array}$ & $\mathrm{PDI}$ & $\begin{array}{c}\text { Zeta potential } \\
{[\mathrm{mV}]}\end{array}$ \\
\hline 1 & $98.0 \pm 0.4$ & 0.333 & $-15.3 \pm 0.1$ \\
\hline 0.1 & $67.1 \pm 0.9$ & 0.164 & $-18.0 \pm 0.5$ \\
\hline 0.01 & $62.3 \pm 1.0$ & 0.150 & $-22.8 \pm 0.6$ \\
\hline 0.001 & $63.3 \pm 1.9$ & 0.119 & $-26.1 \pm 0.2$ \\
\hline 0.0001 & $64.2 \pm 1.7$ & 0.133 & $-36.6 \pm 0.5$ \\
\hline 0 & $67.4 \pm 4.7$ & 0.134 & $-34.2 \pm 0.6$ \\
\hline
\end{tabular}

unchanged at $\mathrm{NaCl}$ concentrations as high as $0.1 \mathrm{M}$ proving that the influence of ionic strength on the colloidal stability can effectively be reduced with silica coating.

In additions, the stability of the Silica-CL-PVA-SPIONs suspended in deionized water was investigated by observing the aggregation and measuring free iron ions released from the particles at different time points. The result showed that the particle was stable for over 9 months. No aggregation and iron solubilisation were observed, indicating a good shelf life of the concentrated particles (Data not shown).

In order to design the nanoparticles utilizable for biomedical applications in vivo, understanding degradation rate and iron ions release from the nanoparticles after cell internalization is important to better understand nanoparticles toxicity and their long term effects. To elucidate the stability of Silica-CL-PVASPIONs in the body, the dissolution of the iron core of the particles was investigated. An in vitro endosomal or lysosomal model was utilized by incubating Silica-CL-PVA-SPIONs in different buffer systems (with or without chelate) at pH 4.5-5.5. Fig. 4 The free iron released from Silica-CL-PVA-SPIONs incubating in endosomal//ysosomal conditions measured from a blue product called Prussian blue $\left(\mathrm{Fe}_{4}\left[\mathrm{Fe}(\mathrm{CN})_{6}\right]_{3}\right)$ absorbed at $690 \mathrm{~nm}$.

The chelating buffer, dicarboxylic acid citrate, which forms stable complexes with $\mathrm{Fe}(\mathrm{III})$ and non-chelating buffer, monocarboxylic acid acetate, which forms less stable complex with $\mathrm{Fe}(\mathrm{III})$ in culture media RPMI 1640 were used as the endosomal/lysosomal model reagents. RPMI 1640 at $\mathrm{pH} 4.5$ and 5.5 were used as non-chelate reagent, while RPMI 1640 at $\mathrm{pH}$ 7.4 and deionized water at $\mathrm{pH} 5.1$ were used as the control reagents which are extracellular/cytoplasmatic $\mathrm{pH}$ and endosomal/lysosomal $\mathrm{pH}$, respectively.

This experiment is based on the hypothesis that endocytosed particles are transferred through endosomes to 


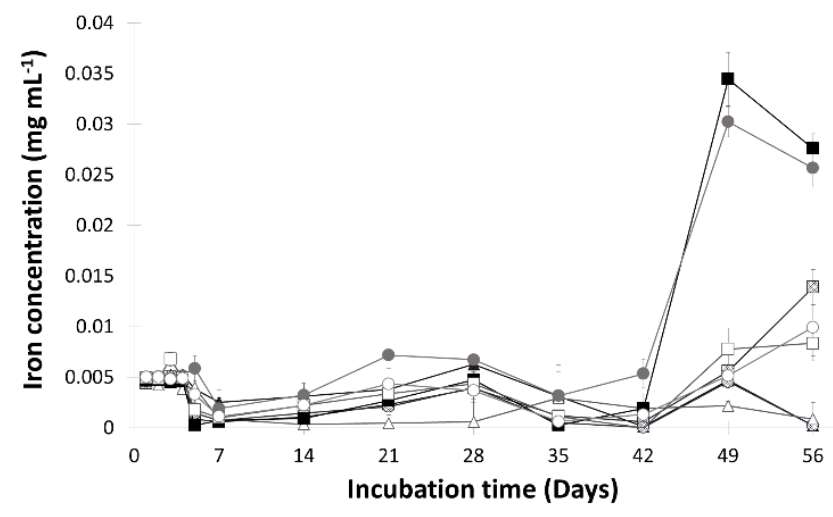

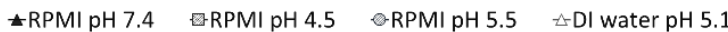

- citrate $\mathrm{pH} 4.5$-citrate $\mathrm{pH} 5.5$-acetate $\mathrm{pH} 4.5$ acetate $\mathrm{pH} 5.5$

lysosomes via intracellular transport pathway where the $\mathrm{pH}$ in lysosomes environment decreases from neutral $\mathrm{pH}$ of 7.4 to acidic $\mathrm{pH}$ of 4.5-5.0. This low $\mathrm{pH}$ may be an important factors promoting solubilisation of the iron oxide particles. In addition, the cellular uptake of iron (Fe) occurs through receptormediated endocytosis of Fe(III)-transferrin complex, followed by dissociation of $\mathrm{Fe}$ (III) from transferrin in a low $\mathrm{pH}$ environment of endosomes and then the released $\mathrm{Fe}$ is transferred into cytosol. This involves binding of the iron to several low molecular weight compounds, such as citrate, and iso-citrate to form complex with Fe and thus contributes to the solubilisation of iron oxide particles. ${ }^{42}$

Previous reports on degradability of superparamagnetic nanoparticles suggested that kinetics of particle dissolution also depends on their surface coating. Lévy et al. compared three distinct surface ligands coating on SPIONs, dextran, citrate (carboxylate), and phosphonate, and found that phosphonate coating particles were more resistant to the particles degradation than carboxylate ligand and dextran coating, respectively. ${ }^{43}$ Dextran-coated magnetic nanoparticles demonstrated the rapid particle decomposition in citrate buffer pH 4.5 within 3 days. ${ }^{12}$ Commercial SPION based MRI contrast agent, oxidized oligomeric starch coating-Clariscan ${ }^{\mathrm{TM}}$ was completely solubilized within 4-7 days when incubated in citrate buffer $\mathrm{pH} 4.5 .{ }^{42}$ In case of silica coating, Malvindi et al. reported silica coating can prevent the degradation of the particles in lysosomal pH of 4.5 as compare to bare particles and the iron solubilisation was observed within 4 days of incubation. ${ }^{44}$

Interestingly, in view of our experimental results, silica coated PVA stabilized SPIONs developed in this work demonstrated dramatically stability improvement in lysosomal condition as compare to previous reports. Our results demonstrated that the low $\mathrm{pH}$ of endosomes/lysosomes and surface coating ligand may be responsible for the kinetics of particles dissolution. As shown in Fig. 4. Silica-CL-PVA-SPIONs started to decompose on day 42 and completely decompose on day 49 at a lysosomal $\mathrm{pH}$ of 4.5 and 5.5 in citrate buffer while on day 49 only minor or no solubilisation on the particle were observed for other reagents. The data obtained with seven different reagents all revealed that the rate of solubilisation was faster in citrate buffer than that in acetate buffer indicating more stable low molecular weight iron-complex of Fe(III)-citrate is the important factor to induce the iron decomposition. Also, we observed a more rapid iron solubilisation in citrate buffer $\mathrm{pH}$
4.5 than at $\mathrm{pH}$ 5.5. The enhanced stability of Silica-CL-PVASPIONs could be attributed to the more compact and stable silica shell created from silanization agents together with PVA passivation on SPION surfaces. This enhances nanoparticles resistance to the acidic condition of lysosomal environment, reducing the degradation of iron core and slowing down the iron ions release.

In addition to determine the free iron solubilisation, the appearance of all reagents was observed during an incubating times. Silica layer of Silica-CL-PVA-SPIONs in citrate buffer may start to detach from the core particles on day 35 as sedimentation of white chemical at the bottom of the test tubes (certainly coming from the silica shell) was observed. However, no solubilisation of SPIONs was observed until day 49. At the end of experiment, the supernatant solution of Silica-CL-PVASPIONs in citrate buffer $\mathrm{pH} 4.5$ appeared as the clear solution without yellow colour of iron. This could attribute to the complete decomposition of the particles and the formation of iron-citrate complex. Other reagents i.e. Silica-CL-PVA-SPIONs in RPMI only and in acetate buffer started to aggregate at day 35 without the decomposition of silica layer and iron solubilisation, while in DI water $\mathrm{pH} 5.1$ no aggregation of the particles was observed (Figure S2).

In aspect of cytotoxicity, nanoparticles toxicity mainly due to intracellular ions release after the degradation. They can react with hydrogen peroxide produced by the mitochondria, inducing the generation of highly reactive hydroxyl radicals and ferric ions (Fe(III)) resulting in cell toxicity. Therefore, considered from long term acidic degradation, the coating we proposed using a cross-linking mixture of PVA and silica allowed to obtain nanoparticles safer to handle for the organism because of more protected to dissolution than with commonly used coatings. Our Silica-CL-PVA-SPIONs will allow time for the cell to process the iron overload by the regulated iron metabolic pathway (at least 42 days) while a faster dissolution of nanoparticles, as presented above (from 3 to 7 days), may lead to an excess of free iron ions, further transferred to the cytosol with possible toxic effects. 
(a)

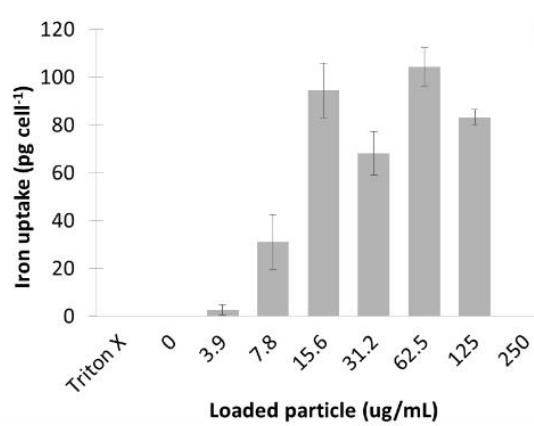

(b)

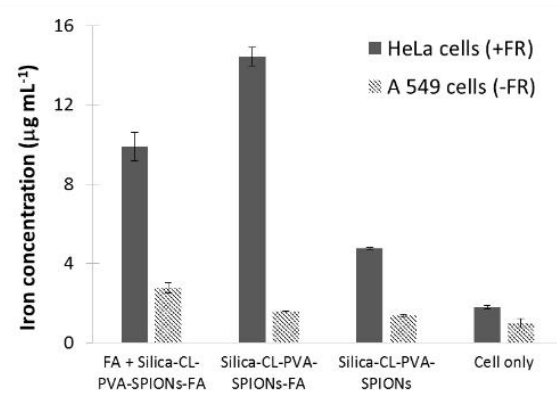

(c)

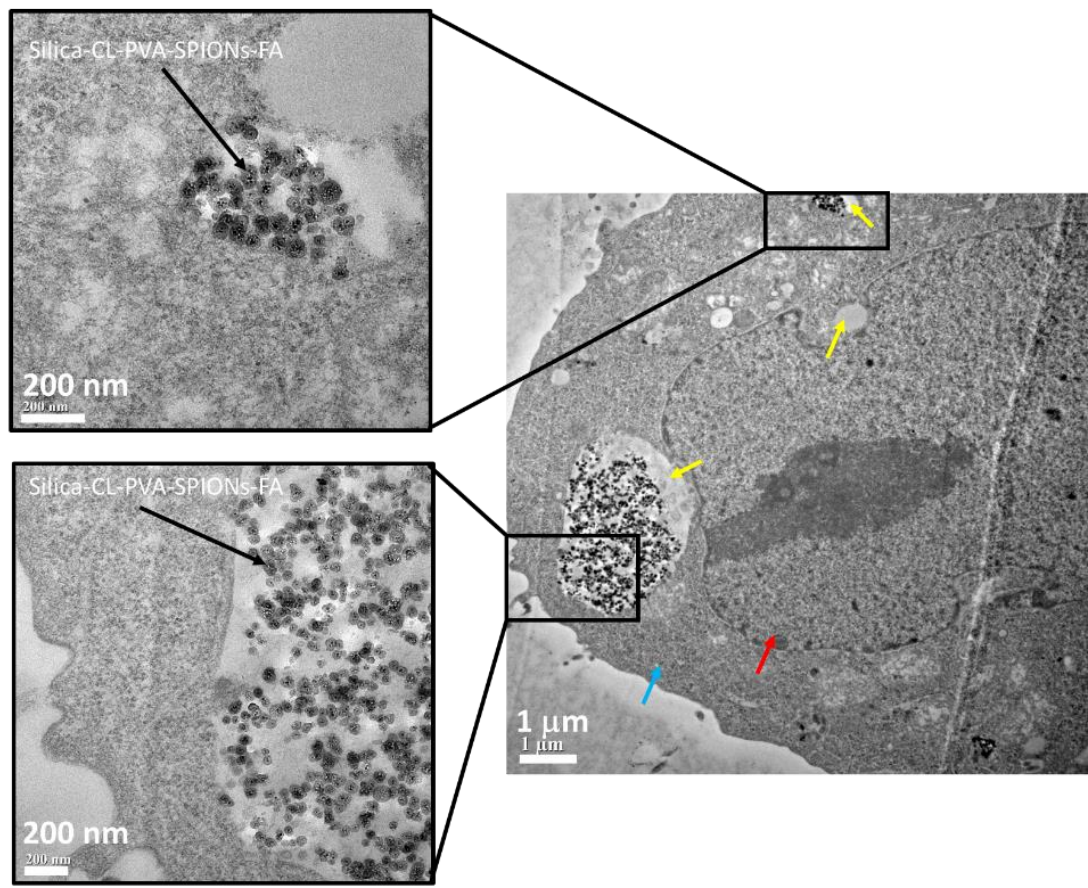

Fig. 5 Preliminary studies on internalization of the particles to HeLa and A549 cells. (a) Iron uptake by HeLa cell at different concentrations of Silica-CL-PVA-SPIONs-FA loaded after incubation for $4 \mathrm{~h}$. (b) The specificity of the Silica-CL-PVA-SPIONs-FA to folate receptor after incubation for $4 \mathrm{~h}$. (c) TEM images and magnified images of treated HeLa cells after incubation with $15.6 \mu \mathrm{gFe} \mathrm{mL}{ }^{-1}$ Silica-CL-PVA-SPIONs-FA for $24 \mathrm{~h}$. Coloured arrows represent selected cell organelles: nuclei (red), cytoplasm (blue) and vacuole (yellow). The black arrow points to Silica-CL-PVA-SPIONs-FA containing vesicle inside cytoplasm of the cell.

\section{Cellular internalization of the particles}

To demonstrate the suitability of Silica-CL-PVA-SPIONs for further use in biomedical applications, folate receptor (FR) which have high affinity to folate was selected as the target model. FR is commonly expressed on the cell surfaces of many human cancers; however, it provides highly selective sites that differentiate tumour cells from normal cells. In this work, in order to bind specifically to folate receptors (FRs), the surfaces of Silica-CL-PVA-SPIONs were modified to amino group using aminopropyl triethoxy silane (APTES) and conjugated to folic acid via EDC/NHS chemistry to form folate reactive Silica-CLPVA-SPIONs-FA. High levels of uptake could be achieved for Silica-CL-PVA-SPIONs-FA at $15.6 \mu \mathrm{gFe} \mathrm{mL}^{-1}$ (Fig. 5(a)). The preliminary studies on internalization of the particles were performed by incubating $15.6 \mu \mathrm{gFe} \mathrm{mL}^{-1}$ the particles to folate receptor (FR)-positive HeLa cells. The iron uptake by cell after 4 $\mathrm{h}$ of incubation revealed the specificity of the particles to folate receptor (Fig. 5(b)). To further confirm that the Silica-CL-PVASPIONs-FA nanoparticles were indeed internalized by the target cells rather than simply bound to the surface of the cells, and to visualize the location of the nanoparticles inside the cells after internalization, TEM images were taken on HeLa cells that were cultured with Silica-CL-PVA-SPIONs-FA nanoparticles. Fig. 5(c) showed the images of HeLa cells treated with Silica-CL-PVASPIONs-FA. The result provides evidence that a large number of Silica-CL-PVA-SPIONs-FA particles accumulated in HeLa cells treated with Silica-CL-PVA-SPIONs-FA and appeared as black dots scattered in the cell cytoplasm but not in the nuclei. A closer look at the images reveals that the majority of the internalized Silica-CL-PVA-SPIONs-FA resided in the lysosomes of the cells. These results explained that Silica-CL-PVA-SPIONsFA could be used for nanomaterial of detecting cancer cells. Moreover, the high stable nanoparticles in lysosomal condition together with high levels of cell uptake may provide these new materials as candidates for use as cell-labelling agents.

\section{Conclusions}

In summary, we demonstrated a facile and up-scalable approach for high stable silica-coated SPIONs synthesis. The encapsulation of polyvinyl alcohol (PVA) on SPION surface before coating of silica is the key factor that improves the biocompatibility and colloidal stability of the particles. The particles provide high colloidal stability at physiological $\mathrm{pH}$ and show long term acidic degradation which are stable under lysosomal condition for up to 42 days without iron solubilisation and sedimentation of the particles indicating the stability of the particles inside the cells. By modifying the particle surface, the particles can be targeted to targeting ligands provide accurate detecting of desired cells and high accumulation in unhealthy tissues. These nanoparticles will have potential in various medical applications such as multiplex detector for disease diagnosis, cancer treatment by hyperthermia therapy, cell labelling agent, as well as MRI contrast agents. 


\section{Acknowledgments}

The authors would like acknowledge the financial support from the National Nanotechnology Center (NANOTEC), National Science and Technology Development Agency (NSTDA), Thailand, the Swiss National Science Foundation (SNSF), Laboratory of Powder Technology, Ecole Polytechnique Fédérale de Lausanne (EPFL), and Faculty of Medicine Siriraj Hospital, Mahidol University.

\section{Notes and references}

₹ Footnotes relating to the main text should appear here. These might include comments relevant to but not central to the matter under discussion, limited experimental and spectral data, and crystallographic data.

1 M. Mahmoudi, H. Hosseinkhani, M. Hosseinkhani, S, Boutry, A. Simchi, W. S. Journeay, K. Subramani and S. Laurent, Chem. Rev., 2011, 111, 253- 280.

2 M. Mahmoudi, V. Serpooshan and S. Laurent, Nanoscale, 2011, 3, 3007-3026.

3 A. K. Peacock, S. I. Cauët, A. Taylor, P. Murray, S. R. Williams, J. V. M. Weaver, D. J. Adams and M. J. Rosseinsky, Chem Commun., 2012, 48, 9373-9375.

4 M. Babič, D. Horák, M. Trchová, P. Jendelová, K. I. Glogarová, P. Lesný, V. Herynek, M. Hájek and E. Syková, Bioconjugate Chem., 2008, 19, 740-750.

5 K. Hayashi, K. Ono, H. Suzuki, M. Sawada, M. Moriya, W. Sakamoto and T. Yogo, ACS Appl. Mater. Interfaces, 2010, 2, 1903-1911.

6 A. Singh, F. Dilnawaz, S. Mewar, U. Sharma, N. R. Jagannathan and S. K. Sahoo, ACS Appl. Mater. Interfaces, 2011, 3, 842-856.

7 Z. Liao, H. Wang, R. Lv, P. Zhao, X. Sun, S. Wang, W. Su, R. Niu and J. Chang, Langmuir, 2011, 27, 3100-3105.

8 S. Tong, S. Hou, Z. Zheng, J. Zhou and G. Bao, Nano Lett., 2010, 10, 4607-4613.

9 N. Sadeghiani, L. S. Barbosa, L. P. Silva, R. B. Azevedo, P. C. Morais and Z. G. M. Lacava, J. Magn. Magn. Mater., 2005, 289, 466-468.

10 X. Y. Wang, S. M. Hussain and G. P. Krestin, Eur Radiol., 2001, 11, 2319-2331.

11 W. Wu, Q. He and C. Jiang, Nanoscale Res Lett., 2008, 3, 397415.

12 A. S. Arbab, L. B. Wilson, P. Ashari, E. K. Jordan, B. K. Lewis and J. A. Frank, NMR Biomed., 2005, 18, 383-389.

13 J. Hradil, A. Pisarev, M. Babič and D. Horák, China Particuology, 2007, 5, 162-168.

14 R. S. Molday, 1984, U.S. Patent 4,452, 773

15 H. W. Kang, L. Josephson, A. Petrovsky, R. Weissleder and A. J. Bogdanov, Bioconjugate Chem., 2002, 1, 102-107.

16 E. K. U. Larsen, T. Nielsen, T. Wittenborn, H. Birkedal, T. VorupJensen, M. H. Jakobsen, L. Østergaard, M. R. Horsman, F. Besenbacher, K. A. Howard and J. Kjems, ACS Nano, 2009, 3, 1947-1951.

17 M. G. P. Saifer, L. D. Williams, M. A. Sobczyk, S. J. Michaels and M. R. Sherman, Mol. Immunol, 2014, 57, 236-246.

18 T. Valdees-Solıs, A. F. Rebolledo, M. Sevilla, P. Valle-Vigon, O. Bomatí-Miguel, A. B. Fuertes and P. Tartaj, Chem. Mater., 2009, 21, 1806-1814.

19 C. Strehl, T. Gaber, L. Maurizi, M. Hahne, R. Rauch, P. Hoff, T. Häupl, M. Hofmann-Amtenbrink, A. R. Poole, H. Hofmann and F. Buttgereit, Int. J. Nanomed., 2015, 10, 3429-3445.

20 A. Bee, R. Massart and S. Neveu, J. Magn. Magn. Mater., 1995, $149,6-9$.

21 M. Mahmoudi, A. Simchi and M. Imani, J. Phys. Chem. C, 2009, 113, 9573-9580.

22 L. Zhou, B. He and F. Zhang, ACS Appl. Mater. Interfaces, 2012, 4, 192-199.
23 F. Schulze, A. Dienelt, S. Geissler, P. Zaslansky, J. Schoon, K. Henzler, P. Guttmann, A. Gramoun, L. A. Crowe, L. Maurizi, J. P. Vallée, H. Hofmann, G. N. Duda and A. Ode, Small, 2014, 10, 4340-4351.

24 F. Schulze, A. Gramoun, L. A Crowe, A. Dienelt, T. Akcan, H. Hofmann, J. P. Vallée, G. N. Duda and A. Ode, Nanomedicine, 2015, 10, 2139-2151.

25 Q. Liu, J. A. Finch and R. Egerton, Chem. Mater., 1998, 10, 3936-3940.

26 C. Hui, C. Shen, J. Tian, L. Bao, H. Ding, C. Li, Y. Tian, X. Shi and H. J. Gao, Nanoscale, 2011, 3, 701-705.

27 A. G. Roca, D. Carmona, N. Miguel-Sancho, O. Bomati-Miguel, F. Balas, C. Piquer and J. Santamaría, Nanotechnology, 2012, 23, 155603.

28 M. S. Iqbal, X. Ma, T. Chen, L. Zhang, W. Ren, L. Xiang and A Wu, J. Mater. Chem. B, 2015, 3, 5172-5181.

29 H. L. Ding, X. Y. Zhang, S. Wang, J. M. Xu, S. C. Su and G. H. Li, Chem. Mater., 2012, 24, 4572-4580.

30 P. Tartaj, T. González-Carreño and C. J. Serna, Adv. Mater., 2001, 13, 1620-1624.

31 Y. A. Barnakov, M. H. Yu and Z. Rosenzweig, Langmuir, 2005, 21, 7524-7527.

32 N. Singh, G. J. S. Jenkins, R. Asadi and S. H. Doak, Nano Reviews, 2010, 1, 5358

33 L. Maurizi, U. Sakulkhu, L. A. Crowe, V. M. Dao, N. Leclaire, J. P. Vallée and H. Hofmann, RSC Adv., 2014, 4, 11142-11146.

34 L. Maurizi, A. Claveau and H. Hofmann, J. Nanomater., 2015, 2015, Article ID 732719.

35 M. Chastellain, A. Petri and H. Hofmann, J. Colloid Interface Sci., 2004, 278, 353-360.

36 F. Sonvico, S. Mornet, S. Vasseur, C. Dubernet, D. Jaillard, J. Degrouard, J. Hoebeke, E. Duguet, P. Colombo and P. Couvreur, Bioconjug Chem., 2005, 16, 1181-1188.

37 R. Yang, Y. An, F. Miao, M. Li, P. Liu and Q. Tang, Int. J. Nanomedicine, 2014, 9, 4231-4243.

38 T. Pan, S. Khare, F. Ackah, B. Huang, W. Zhang, S. Gabos, C. Jin and M. Stampfl, Comput. Biol. Chem., 2013, 47, 113-120.

39 H. Benachour, T. Bastogne, M. Toussaint, Y. Chemli, A. Seève, C. Frochot, F. Lux, O. Tillement, R. Vanderesse and M. BarberiHeyob, PLoS ONE, 2012, 7, e48617.

40 Z. Teng, X. Kuang, J. Wang and X. Zhang, J. Virol. Methods, 2013, 193, 364-370.

41 L. Otero-González, R. Sierra-Alvarez, S. Boitana and J. A. Field, Environ. Sci. Technol., 2012, 46, 10271-10278.

42 T. Skotland, P. C. Sontum and I. Oulie, J. Pharmaceut. Biomed., 2002, 28, 323-329.

43 M. Lévy, F. Lagarde, V. Maraloiu, M. Blanchin, F. Gendron, C. Wilhelm and F. Gazeau, Nanotechnology, 2010, 21, 395103.

44 M. A. Malvindi, V. D. Matteis, A. Galeone, V. Brunetti,G. C. Anyfantis, A. Athanassiou, R. Cingolani and P. P. Pompa, PLoS ONE, 2014, 9, e85835.

45 M. H. Majd, D. Asgari, J. Barar, H. Valizadeh, V. Kafil, G. Coukos and Y. Omidi, J. Drug Target., 2013, 21, 328-340. 